\title{
\% *ABPPOO

\section{A LIMITAÇÃO DA JORNADA DE TRABALHO E OS IMPACTOS NA SAÚDE DOS CEGONHEIROS}

\section{THE WORKING DAY LIMITATION AND IMPACTS ON THE HEALTH OF STORK DRIVERS}

\author{
Daniela Emma Grossi Roppoli* E-mail: daniela roppoli@yahoo.it \\ Maria Elizabeth Antunes Lima* E-mail: maria.lima@unihorizontes.br \\ ${ }^{*}$ Centro Universitário Novos Horizontes, Belo Horizonte, MG
}

\begin{abstract}
Resumo: Este estudo foi desenvolvido após muitos debates na nossa sociedade, relacionando o uso de drogas pelos motoristas profissionais com a organização do trabalho à qual são expostos. $O$ prazo curto para realizarem as entregas, as jornadas prolongadas, o pagamento por produtividade, são fatores que levam, muitas vezes, esses profissionais recorrerem às drogas psicoativas, de modo a se manterem acordados e atingirem as metas que Ihes foram impostas. Dessa forma, o objetivo foi conhecer os impactos da regulamentação da jornada de trabalho sobre a saúde dos motoristas profissionais, mais precisamente os cegonheiros. O campo de pesquisa foi uma empresa privada de médio porte, que opera na área de logística de automóveis novos, situada em Betim - MG. Tratou-se de um estudo de caso, baseado em observações em campo, análise documental e entrevistas com seis cegonheiros, o gerente de produção, o gerente de saúde e segurança e o proprietário da empresa, sendo adotado o critério de saturação. Os resultados permitiram constatar que, na empresa estudada, a jornada de trabalho é bem controlada dentro de uma atividade de caráter variável, o que reduz a fadiga dos motoristas. As pausas durante as viagens a trabalho, são respeitadas e representam um importante mecanismo de regulação, prevenção de doenças e até mesmo de acidentes, pois os motoristas trabalham descansados e não sentem necessidade de recorrer a substâncias psicoativas para manter a vigilância. O estudo traz contribuições para a prevenção do uso de substâncias psicoativas, acidentes de trabalho e outros problemas que afetam a saúde dos motoristas profissionais. Sua limitação maior consiste na dificuldade em confrontar seus resultados com outras pesquisas devido à escassez da literatura e de dados estatísticos atualizados sobre o tema.
\end{abstract}

Palavras-chave: Nova Lei do Motorista Profissional. Organização do Trabalho. Cegonheiros. Saúde.

Abstract: This study was developed After long debates in our Society in a matter of the use of drugs by professional drivers with the scale of their jobs witch they are exposed. The short period of time to deal with their package delivery, the long work journey instead of scale, payment per productivity, are facts that, so many times, force then to look for psychoactive drugs, in order to keep themselves awake and fulfill their goal, which had been demanded to them. Therefore, the objective was to get knowledge about the regimentation of their work journey on the health of the professional drivers, most specifically the car-carrier truck drivers. The research field was a medium size company, that works in logistic segment of brand-new cars, located in Betim-MG. This was a case study, based on field observations, documentary analysis and interviews with six storers, the production manager, the health and safety manager and the owner of the company, and the saturation criterion was adopted. The results allowed the understanding that, in the company studied, the work journey is well controlled in a variable character perspective, that's what reduces the drivers fatigue. The pauses during the travels are respected as well and it represents an important regulation mechanism, foresing diseases and even accidents, because the drivers work while rested and they don't have the needing of the use of psychoactive drugs to keep them awake. The study brings the contribution to prevent the use of psychoactive substances, work accidents and other problems that might disturb the professional driver's health. It's only limitation is in a matter of the difficulty to compare it's results with other researches because of the scarcity of literature and updated statistic data about the theme as well. 
Keywords: New Professional Driver Law. Labour Organization. Stork Drivers. Health.

\section{INTRODUÇÃO}

Um estudo sobre a vida e o trabalho dos caminhoneiros realizado por Santos (2004) revelou que o Brasil é um país com um grande número de motoristas profissionais, distribuídos de forma bastante heterogênea quanto aos locais de trabalho.

Para 0 atendimento do curto prazo estabelecido para as entregas, os motoristas, muitas vezes, devem estender a jornada de trabalho, podendo recorrer a um meio que vem sendo considerado um sério problema na categoria: o uso de substâncias psicoativas. Para melhor entender essa maneira de responder às exigências temporais das entregas, o procurador do Ministério Público do Trabalho da 24a região, Paulo Douglas Almeida de Moraes, em 2007, desenvolveu um estudo especificamente voltado para a realidade da categoria de motoristas profissionais, observando dados importantes, como descritos a seguir:

\footnotetext{
Em 2007, quando estivemos em Rondonópolis, no início da carreira no Ministério Público (...) fomos às rodovias e constatamos, naquela oportunidade (...), $22 \%$ de positividade clínica. Paramos 100 motoristas e constatamos $22 \%$ deles usando alguma espécie de substância e imaginávamos, num primeiro momento, que seria anfetamina.[Foi constatado que] $68 \%$ usavam cocaína e 32\% anfetamina (MORAES, 2014, p. 79).
}

Se o cenário já era crítico em 2007, em 2012, o número de usuários de cocaína nessa categoria não só aumentou, mas tornou-se mais grave, já que passaram a usar um coquetel de drogas, isto é, uma mistura de substâncias psicoativas para ficarem acordados e, em seguida, barbitúricos para conseguirem dormir (MORAES, 2014).

Esses dados deram impulso para que se iniciasse uma nova discussão, levando ao desenvolvimento da Lei do Motorista Profissional, no. 12.619/20121 , que passou a regulamentar a jornada de trabalho para 8 horas diárias com 30 minutos de descanso intrajornada a cada 4 horas de direção e 2 horas extraordinárias. Em 2015, essa Lei foi substituída pela Lei de no. 13.103, fracionando o tempo de descanso, de

\footnotetext{
${ }^{1}$ Lei sancionada em 30 de abril de 2012 que restringe a jornada diária do trabalho do motorista profissional para oito horas e inclui tempo de descanso de 30 minutos intrajornada. Disponível em: <http://www.planalto.gov.br/ccivil_03/_Ato2015-2018/2015/Lei/L13103.htm>.
} 
forma que os 30 minutos de descanso poderiam ser realizados pelo motorista dentro de uma janela de $05 \mathrm{~h}$ e $30 \mathrm{~min}$, ficando à sua escolha decidir o melhor momento para fazer a pausa. Além disso, as horas extraordinárias por jornada foram aumentadas para quatro, de acordo com convenção coletiva, mantendo o recebimento por produtividade, como complementação do salário. Ambas as leis trazem a obrigatoriedade da realização do exame toxicológico no momento da contratação e desligamento do empregado da empresa.

É sabido que a organização dos horários e das escalas de trabalho em turnos ou até mesmo turnos irregulares, pode potencializar o desenvolvimento de doenças psicofisiológicas, dentre elas, transtornos alimentares e do sono. (FERREIRA e ALVAREZ, 2013). No caso do motorista profissional, o problema possui relevância para a saúde pública, uma vez que, a organização inadequada do trabalho, gera um aumento considerável do risco de acidentes (MORENO e ROTEMBERG, 2009).

Diante disso, nossa pesquisa teve por finalidade principal compreender melhor os impactos que as limitações das jornadas de trabalho, proporcionadas pela nova legislação, tiveram sobre a saúde dos cegonheiros, bem como sobre a segurança nas estradas.

\section{GENOCÍDIO RODOVIÁRIO NO BRASIL}

A expressão "genocídio rodoviário" foi cunhada, em 2012, pelo já citado procurador do Ministério Público do Trabalho da 24a Região do Estado de Mato Grosso do Sul, Paulo Douglas Almeida de Moraes, em um artigo no qual criticou o sistema de transporte rodoviário no Brasil, devido aos baixos salários, pagamentos por produtividade, jornadas prolongadas e uso de drogas. Ele também discutiu as dificuldades presentes na implementação da Lei do Motorista, considerando os interesses, quase sempre contraditórios, entre motoristas, sindicalistas, empresas e governo (MORAES, 2012).

O Brasil possui uma grande estrutura de transporte de cargas rodoviárias e os protagonistas desse sistema são os motoristas. Eles são responsáveis pelo atendimento de contratos de transporte que determinam prazos de entrega e, do seu desempenho profissional, depende, em grande medida, o dinamismo da economia do país. Esse trabalho diário abastece todas as cidades brasileiras e os desafios que 
enfrentam envolvem, desde estradas sem conservação, afastamento da família e problemas com assaltos, até os riscos de sofrerem acidentes (ANDRADE et al., 2012).

Sua atividade pode ser considerada como penosa, sobretudo, devido à pressão temporal para efetivarem as entregas em tempo hábil; as jornadas prolongadas de trabalho; a possibilidade de vivenciar ou presenciar acidentes de trânsito; os riscos de sofrerem assaltos; a necessidade de manter uma atenção constante; o horário incerto para as refeições; os movimentos repetitivos; a solidão; a monotonia; os problemas com a quantidade e a qualidade do sono; as más condições materiais e ambientais de trabalho; a responsabilidade com a preservação da carga transportada; e as preocupações de ordem econômica (HOFFMANN, 2003).

Segundo Waltrich (2014), as diversas contribuições que esses milhares de profissionais da estrada proporcionam para a sociedade são conhecidas. Entretanto, poucos benefícios lhes são oferecidos, uma vez que a taxa de mortalidade por acidentes atinge níveis altíssimos e, em sua maioria, devido à grande extensão da sua jornada de trabalho.

Esses problemas não parecem ser exclusivos do nosso país, uma vez que, em vários países, tem sido constatado o uso excessivo de álcool, cigarros e anfetaminas por essa categoria profissional (LACERDA et al., 1997; STRATFORD et al., 2000; SILVA et al., 2003; UBAIDULLAH, 2004; FERRAZ, 2005; NASCIMENTO et al., 2007). Estudos realizados na Europa, África e Brasil, demonstraram que motoristas de caminhão apresentam problemas relacionados à saúde e ao estilo de vida, além de grande vulnerabilidade às práticas de risco, pelo uso de drogas (MASSON e MONTEIRO, 2010).

O reduzido tempo para o descanso, a ausência do sono reparador, associada ou não ao uso de substâncias psicoativas, se apresentam como preocupantes causas de acidentes em rodovias, envolvendo esses trabalhadores. Sabe-se que a fadiga é considerada como uma das maiores causas dos acidentes rodoviários, podendo acometer o motorista logo na primeira metade de sua viagem (LYZNICKI et al., 1998; McCARTT et al., 2000).

Todos esses aspectos têm levado à interrogação sobre o caráter dessa atividade profissional, considerando a extrema gravidade das estatísticas: 
Federal. Como evoluiu isso de 2007 para 2011? Em 2007, assistíamos a 103 mil acidentes. Em 2011, pulamos para 192. Feridos: de 65 mil para 106 mil. Mortos: de cinco mil e oitocentos para oito mil e seiscentos. Isso apenas em rodovias federais policiadas. O número de mortos (...) chega à casa de 43 mil, de um modo geral (MORAES, 2014, p. 80).

Moraes (2014) ressalta ainda que esses números indicam que os acidentes de trabalho do setor do transporte superaram os da construção civil no aspecto de letalidade.

Em um estudo transversal realizado em 2010, com 460 motoristas de caminhão de uma transportadora de cargas das regiões Sul e Sudeste do Brasil, os autores constataram uma estreita relação entre a falta de regulamentação da jornada de trabalho e o desenvolvimento dos chamados "Distúrbios Psíquicos Menores" (DPM) (ULHOA et al., 2010).

No ano de 2007, o Ministério Público do Trabalho iniciou, na cidade de Rondonópolis/MT, uma tentativa de aproximação da realidade nas estradas, por meio de uma pesquisa, baseada na coleta de urina dos motoristas de cargas. Houve várias recusas, mas entre os que autorizaram a coleta, foram feitas as aferições e várias constataram o uso de drogas. Foi então ajuizada uma ação civil pública que contou com o deferimento liminar pelo Juízo da $1^{\underline{a}}$ Vara de Rondonópolis, provocando um novo debate em torno dos problemas do transporte rodoviário. Essa discussão durou quatro anos e culminou na Lei oㅜ 12.619/2012, denominada aqui, Lei do Motorista Profissional. Esta lei resultou de um esforço interinstitucional, com destaque especial para a Polícia Rodoviária Federal, e teve por foco o combate às três maiores dificuldades que afetam o atual sistema de transporte: descontrole de jornada, baixa remuneração e pagamento por produtividade (MORAES, 2012).

\section{O MÉTODO DE PESQUISA}

A pesquisa foi realizada em uma empresa que atua no segmento de transporte de automóveis, sendo que os sujeitos foram escolhidos por critério de disponibilidade, uma vez que seus horários de trabalho eram variáveis, dificultando o agendamento prévio. Os instrumentos de coleta de dados foram observação de campo, entrevista individual e análise documental. As entrevistas foram baseadas em perguntas abertas, de forma a permitir respostas mais amplas e o aprofundamento dos temas considerados essenciais. Os sujeitos foram abordados acerca de assuntos 
envolvendo seus dados pessoais e profissionais: (1) impactos da sua profissão na vida familiar, além dos sentimentos em relação ao trabalho e à empresa; (2) aspectos relativos ao modelo de gestão adotado pela empresa e possíveis fatores estressores a eles associados, além das questões relativas às mudanças provocadas pela nova legislação e outros aspectos mais diretamente relacionados com a problemática da pesquisa. Foram realizadas nove entrevistas, sendo seis com cegonheiros, uma com a gerência operacional, uma com o proprietário da empresa e uma com a coordenadora da empresa terceirizada de saúde e segurança. O critério adotado foi o de saturação, isto é, as entrevistas cessaram assim que os dados começaram a se repetir, indicando que não encontraríamos novas informações junto a outros entrevistados. Foram também levantados os dados de saúde relacionados com afastamentos ocupacionais, com base em informações de prontuários médicos.

As entrevistas foram gravadas transcritas e submetidas a uma análise de conteúdo, na modalidade de análise temática, resultando na definição dos principais temas identificados nas respostas. Para sua efetivação, foram adotadas as etapas de tratamento apresentadas por Melo et al.(2007): organização sistemática dos dados coletados, tabulação e categorização temática.

No que tange às questões éticas, os sujeitos participantes foram informados sobre os objetivos da pesquisa e, posteriormente, foi colhida a assinatura do Termo de Consentimento Livre e Esclarecido. O estudo seguiu as orientações da Resolução de número 466 de 12 de dezembro de 2012 do Conselho Nacional de Saúde.

\subsection{RESULTADOS DA PESQUISA}

Todos os cegonheiros entrevistados eram contratados pela empresa, em conformidade com a Consolidação das Leis do Trabalho (CLT) e realizavam viagens ao longo do território brasileiro. Os participantes da pesquisa serão identificados aqui por GO (gerente operacional), PE (proprietário da empresa), C1 a C6 (cegonheiros de um a seis) e CSS (coordenadora da empresa de saúde e segurança).

A empresa pesquisada tem 25 anos de existência e atua no transporte de veículos e produtos inflamáveis. Está localizada em Betim, Minas Gerais, e atende a todo o território nacional. Possui administração familiar e um dos donos, devido à idade avançada, passou a administração ao seu filho citado ao longo da pesquisa 
como o proprietário da empresa (PE). Existe outro sócio, que, no passado, trabalhou como motorista de cegonha e que realiza algumas atividades na administração do sindicato dos cegonheiros.

O quadro é constituído por 33 empregados, sendo 19 cegonheiros que possuem Carteira Nacional de Habilitação $(\mathrm{CNH})$ categoria E. Seu salário é composto por um valor fixo, somado com as diárias, horas de espera e comissão sobre o lucro, sendo que esta varia de acordo com o valor da carga. Portanto, quanto maior o número de viagens e mais valorizada for a carga, maior será a comissão.

\subsubsection{Perfil dos cegonheiros entrevistados}

Encontramos uma presença absoluta de motoristas do sexo masculino, apresentando faixas etárias variadas, de 26 a 51 anos, predominantemente acima de 35 anos. Quanto à escolaridade, dois têm $2^{\circ}$ grau completo; dois têm $1^{\circ}$ grau incompleto; um tem $2^{\circ}$ grau incompleto e outro $1^{\circ}$ grau completo.

Sobre o estado civil, dois são divorciados, três estão em regime de união estável e apenas um é solteiro, sendo também o único que não tem filhos. Este último manifestou uma forte rejeição à ideia de constituir uma família e não poder acompanhar o crescimento dos filhos, devido às exigências da profissão. Já seus colegas expressaram o hábito de viver a maior parte do tempo distantes da família, não expressando qualquer pesar em relação à impossibilidade de acompanhar o desenvolvimento e a educação dos filhos.

\subsubsection{Experiência profissional e relação com a profissão}

Quanto ao tempo que trabalham na área, os três cegonheiros mais velhos possuem ampla experiência, de dezenove a vinte e cinco anos, sendo que os mais jovens atuam apenas há três anos na função. O cegonheiro mais velho é também o que possui o maior tempo na empresa estudada. 
Tabela 1 - Trajetória profissional

\begin{tabular}{r|r|rrr}
\hline \hline Siglas & Idade & \multicolumn{1}{|c}{$\begin{array}{c}\text { Tempo de profissão } \\
\text { caminhoneiro }\end{array}$} & $\begin{array}{c}\text { Tempo na } \\
\text { função } \\
\text { Cegonheiro }\end{array}$ & $\begin{array}{r}\text { Tempo na função cegonheiro na } \\
\text { empresa pesquisada }\end{array}$ \\
\hline C1 & $\mathbf{2 6}$ & 7 anos & 3 anos & 2 anos \\
C2 & $\mathbf{2 8}$ & 6 anos & 3 anos & 1 ano e meio \\
C3 & $\mathbf{3 7}$ & 16 anos & 3 anos & 7 meses \\
C4 & $\mathbf{3 9}$ & 19 anos & 11 anos & 9 anos \\
C5 & $\mathbf{4 3}$ & 25 anos & 12 anos & 4 anos \\
C6 & $\mathbf{5 1}$ & 25 anos & 25 anos & 23 anos \\
\hline \hline
\end{tabular}

Fonte: Dados da pesquisa

Em geral, eles afirmaram sentir prazer no cotidiano de trabalho, afirmando que este Ihes traz satisfação, liberdade e sentimento de realização. Apenas o mais jovem relatou que não irá permanecer na atividade por muito tempo, devido à distância que essa profissão impõe em relação aos familiares e amigos.

\subsubsection{As características da carga}

Sobre as maiores dificuldades presentes no transporte da carga de veículos, todos se referiram à exigência de entrega do produto sem avarias. Estas podem ocorrer por diversos fatores, sendo os cabeamentos elétricos baixos em rodovias e cidades o fator mais preocupante, seguidos de galhos de árvores, pontes e viadutos baixos. Outros elementos citados foram: chuva de granizo, pedras, circulação em vias estreitas dentro de pequenas cidades, além do fato de não ser possível ver carro pequeno e moto pelos retrovisores.

De modo geral, eles expressaram receio ao transportar uma carga de alto valor, pois ainda que seja segurada, o seguro para esse tipo de carga não abrange avarias provocadas por todos os sinistros.

Depende muito do tipo de situação para a cobertura do seguro. Eles olham tudo: velocidade, o tipo de avaria, a situação que causou o acidente e de quem foi a culpa. Embora seja dessa forma, nunca tivemos problemas sérios de avarias. Exceto um tombamento que tivemos, mas o seguro cobriu. A penalização do cegonheiro foi que o nosso embarcador o suspendeu por dois dias de realizar viagens (GO).

Segundo os entrevistados, essa carga é percebida de forma diferenciada pelos outros motoristas, que reservam aos cegonheiros um tratamento distante e hostil: 
Eles acham que a gente é mais metido, sei lá... Nas paradas têm os motoristas de caminhão que quando vê a gente, olha meio torto. Vejo que existe esse preconceito... Que eles acham que somos mais que eles. Só que isso já foi até pior, agora isso vem melhorando... E não tem nada a ver pensar isso. Tamos tudo no mesmo barco (C4).

No entanto, alguns entrevistados percebem também um diferencial no tipo de carga que transportam, ao se definirem como "transportadores de sonhos":

Os cegonheiros são transportadores de sonhos. Eles sabem que todas as pessoas sonham em ter seu carro próprio (GO).

\subsubsection{O risco de assalto}

Sobre a possibilidade de ocorrerem assaltos, a maioria se mostrou tranquila, dizendo que o tipo de mercadoria que transporta não é muito visada pelos assaltantes, já que se trata de uma carga rastreada, de difícil retirada. Seria necessário ter a chave do veículo, destravá-lo (roda por roda), retirar rampas internas da carreta (de ferro) para posicionar no chão além de manobrar os veículos em inclinações e alturas diferenciadas devido aos remontes da carreta.

Mas isso não impede que alguns demonstrem certa preocupação com assaltos, embora, entre os três que já haviam sido assaltados, dois viveram a experiência quando trabalharam em outra empresa e apenas um na empresa pesquisada.

[...] Eles me abordaram na estrada e levaram a carreta. Subiram na carreta e mandaram eu colocar a mão na cabeça, soltaram a mangueira de ar. Aí, ela travou e a carreta travou no meio da pista. O ladrão abriu a porta e apontou o revólver e mandou eu deitar de bruços e colocar as mãos para trás. Ele ficou com a arma nas minhas costas. Enquanto isso, o outro foi dirigindo a carreta e desligou o rastreador com o chupa cabra. Esse aparelho desativa rastreadores. Me deixaram no meio do mato onde fiquei a noite inteira. Depois disso, passei uma semana em casa. Depois, retornei ao trabalho, mas precisei de duas semanas para começar a esquecer o que passou. A empresa deu todo o suporte. Até psicóloga perguntaram se era necessário, mas não precisei. Foi um susto e passou. Voltei a trabalhar normal e não ter insônia (C5).

Além disso, o fato de transportarem veículos novos, sendo, muitas vezes, lançamentos das montadoras, atrai a atenção das pessoas nas estradas, sendo que algumas reduzem a velocidade e olham para a carreta e para os veículos. Isso faz com que sintam receio por não saberem se é um possível assaltante ou somente um curioso. Seja como for, esses relatos revelam a presença de tensão, medo e mesmo certo trauma dos assaltos sofridos. 


\subsubsection{O estilo de liderança adotado na empresa}

As descrições oferecidas pelos entrevistados, a respeito do tipo de gestão adotado na empresa, sugerem que prevalece um estilo de liderança mais aberto, com resoluções rápidas, flexibilidade para tratamento dos assuntos profissionais, valorizando a comunicação com os subordinados, conforme TAB. 2.

Tabela 2 - Percepção quanto à liderança

\begin{tabular}{lc}
\hline \multicolumn{1}{c}{ Percepção quanto à liderança } & № de respostas \\
\hline Disponível & 4 \\
Rápido nas resoluções de problemas & 3 \\
Boa participação nas situações imprevisíveis & 4 \\
Amigo & 2 \\
Comunicativo & 4 \\
Ótimo & 4 \\
\hline
\end{tabular}

Fonte: Dados da pesquisa

Nota: *A soma das frequências é superior a 6 por ter sido possível que os entrevistados dessem mais de uma resposta

\subsubsection{Características da atividade dos cegonheiros e as práticas organizacionais}

As tarefas dos cegonheiros, isto é, a prescrição do que devem fazer consiste em: transportar veículos novos e usados, carregando e descarregando os remontes da carreta, mantendo os veículos sem avarias até o seu descarregamento.

Sua rotina, que será descrita a seguir, foi reconstituída a partir de observações do seu trabalho e por meios das entrevistas.

O transporte de veículos é considerado como uma atividade, cujo valor agregado por quilômetro rodado, é o um dos maiores no Brasil. Assim, os fretes repassados às transportadoras são, em geral, um dos mais bem pagos. Considerando os valores que são agregados e o número de empresas automobilísticas no Brasil, a atividade do cegonheiro move grande parte da economia do país.

Podemos transportar valores enormes e percorrer percursos mais curtos se compararmos com outros tipos de carga. Variando de 300 mil com 11 unos até a 2 milhões com Jaguar (GO).

Ao iniciar a jornada, o operador logístico vai até os clientes, chamados embarcadores, a fim de verificar no sistema eletrônico de distribuição de carga, as 
viagens que irão acontecer. Verifica também como está a fila de viagens para distribuir entre os cegonheiros.

O tipo de viagem agendada pelo operador logístico é muito importante, pois existem cargas mais estratégicas, como vemos no depoimento abaixo:

\begin{abstract}
As cidades mais longe são melhores, pois nosso lucro que tiramos do frete é proporcional à distância percorrida. Melhora o extra (risos). E também, quando deixamos muitos veículos em uma concessionária, ao invés de largar três veículos em uma cidade, dois em outra e assim vai (C2).
\end{abstract}

A meta em geral, instituída por rodagem, propõe uma média de 400 a $500 \mathrm{~km}$ por dia, sendo que o planejamento de $400 \mathrm{~km} /$ dia ocorre quando as estradas apresentam piores condições e o de $500 \mathrm{~km} / \mathrm{dia}$, quando as condições estão melhores. Antes de cada viagem, cada cegonheiro deve fazer o check list dos itens de manutenção e, caso encontre qualquer problema, deve comunicar ao gerente operacional para as devidas providências. Em caso de conformidade, preenche 0 diário de bordo anotando o início da jornada. O diário de bordo é onde fazem todos os apontamentos referentes à viagem. Devem informar aspectos, como: identificação da frota, quilômetro inicial, dia, horário de início da viagem, descanso da direção, almoço, jantar, realização de sobrejornadas, interstício diário, espera da carga, espera de descarga, tempo de direção, jornada de trabalho, enfim, todas as ocorrências importantes da viagem.

Após o preenchimento do check list, o cegonheiro se dirige até ao pátio do embarcador (empresa - cliente), que se localiza a $2 \mathrm{~km}$ de distância, faz a apresentação da nota detalhada do carregamento e se posiciona na rampa que lhe é indicada. Dessa forma, a carreta fica posicionada para que uma equipe de motoristas de carregamento transfira para ela a carga dos veículos já inspecionados. Assim que os veículos são posicionados sobre a carreta, com freio de mão engatado, a equipe de amarradores faz a amarração de roda por roda de cada veículo, com objetivo de manter a segurança durante a viagem, enquanto o cegonheiro aguarda. Alguns inspecionam os veículos por fora para verificar avarias, outros confiam no trabalho da equipe do embarcador. Após a carga pronta, os amarradores colocam a placa de fechamento ao final da carreta, o cegonheiro faz a checagem de amarração da carga e, então, pode receber a nota fiscal com dados de cada veículo. A carga pode ser fechada, isto é, pode ocorrer na forma de uma única entrega em uma única 
concessionária, ou fracionada, isto é, conter diversas mercadorias para serem entregues em etapas. Essa segunda modalidade não rende muito em termos de tempo e em comissões, pois são vários deslocamentos para deixar poucos veículos.

Logo após receber a nota fiscal, o motorista segue viagem. Em geral, os mais experientes conhecem as rotas, mas em caso de novatos ou quando o destino é alguma cidade desconhecida, o gerente operacional dá todas as instruções necessárias, incluindo os postos credenciados para pontos de parada e abastecimento. Os cegonheiros relataram que a maior dificuldade encontrada em todo esse processo, encontra-se na demora no carregamento e no descarregamento. Mas sabem que esse tempo está incluído na meta diária de tempo de trabalho.

A empresa transmite todas as regras de circulação de cada rodovia para os novatos e reforça para os veteranos. A velocidade permitida para rodagem é de até $90 \mathrm{~km} / \mathrm{h}$, embora outras empresas permitam $95 \mathrm{~km} / \mathrm{h}$, uma vez que o seu objetivo é o de aumentar a segurança. Há um controle por tacógrafo, sendo que podem exceder o limite somente em casos de ultrapassagens ou outras circunstâncias excepcionais. Todos os cegonheiros entrevistados concordaram com essa norma, expondo que, no passado, em outras empresas, eles excediam a velocidade e não era incomum a ocorrência de acidentes.

[...] Aqui na empresa, sempre andamos freados. Isso é melhor que correr e perder a vida. Parece pouco andar cinco quilômetros a menos, mas faz muita diferença. O peso da carreta no momento de frear em alta velocidade é quase impossível de conter um acidente (C1).

Toda cegonha possui um rastreador que permite o controle via satélite durante $24 \mathrm{~h}$ por dia, atualizando os dados a cada cinco minutos, sendo monitorado por computadores da empresa e pelos smartphones do gerente e do dono, proporcionando informações de localização, velocidade e horário. É possível programar o rastreador para acionar um bip a cada limite de velocidade excedido e em caso de mudança de rota. Esta última pode ser uma informação importante, indicando, por exemplo, roubo da carreta, uma vez que, em geral, quando o cegonheiro decide mudar, envia um comunicado justificando a mudança para a empresa. 


\subsubsection{As condições gerais de trabalho}

As cabines das carretas possuem uma boa estrutura e oferecem certo conforto para o motorista. O local para dormir é espaçoso, possuindo dimensões próximas das medidas de uma cama de solteiro. As cortinas escurecem o ambiente e existe ar condicionado. Nenhum motorista relatou ter receio de dormir na cabine por questão de segurança, já que todos consideram esse espaço bem seguro, uma vez que as portas possuem sistema de travas, além da possibilidade de rastreamento da carreta.

Para maior segurança e conforto, as paradas para abastecimentos são realizadas em postos parceiros da empresa, sendo que estes são inúmeros ao longo de todos os trechos em território nacional. Os pernoites em geral também acontecem dessa forma, salvo algumas exceções.

Temos que parar em postos seguros, especialmente para dormir. Isso nos dá mais segurança, pois lá conhecemos o lugar, as pessoas e o sistema de segurança (C6).

É comum os postos cobrarem uma taxa de cada carreta por noite, mas os cegonheiros recebem um valor de diária que prevê esses custos, além daqueles com alimentação.

As paradas para refeição e descanso também ocorrem em lugares conhecidos onde, geralmente, há boa comida e bons banheiros, embora a qualidade das refeições sempre dependa da região onde trafegam. A alimentação nos percursos que vão, por exemplo, no sentido nordeste, é mais "gordurosa", segundo eles, do que no sentido sudoeste, o que é motivo de insatisfação.

Sobre as questões relativas ao trânsito, intempéries da natureza e acidentes, não houve relato de dificuldades, sendo que a maioria considera que administra bem os problemas no trânsito, solicitando, sempre que possível autorização da empresa para mudança de rota, em casos de acidentes ou imprevistos. Quando o clima é de chuva ou neblina, eles preferem ser mais cautelosos nas estradas, rodando com velocidades ainda menores e ocupando a faixa da direita.

O proprietário da empresa relatou a ocorrência de apenas um acidente no período de 2010-2011:

Aqui na empresa não sabemos o que é acidentes e doenças. Desde antes da lei, sempre fizemos de tudo para não exceder a rotina dos motoristas. 
Sabemos do risco que é pegar estrada, cansado. Não dormir direito. O impacto disso, na saúde e na segurança. No ano de 2010-2011, tivemos um tombamento de carga. Aqui é assim, índices próximos do zero (DE).

Se considerarmos que esse ramo de atividade apresenta índices bem mais elevados de acidentes, podemos atribuir esses índices reduzidos da empresa estudada, à sua adequada organização do trabalho, envolvendo uma boa gestão do tempo de entrega e o respeito ao descanso do cegonheiro.

Em caso de falhas mecânicas ou elétricas, ou qualquer outro problema, os cegonheiros se comunicam com o gerente ou a secretária da empresa, por meio de celular. Nenhum deles se queixou de dificuldades em se comunicar rapidamente com a empresa. Em geral, quando o problema é complexo, os responsáveis enviam a seguradora até o local ou autorizam o motorista a procurar ajuda em alguma cidade mais próxima. Se o problema for simples, o próprio cegonheiro resolve e comunica à empresa. Todas as intercorrências devem ser anotadas no diário de bordo.

\subsubsection{As regras de rodagem}

Os cegonheiros devem obedecer às regras de rodagens de acordo com cada rodovia. As rodovias federais permanecem sob a administração do Departamento Nacional de Infraestrutura de Transportes (DNIT) à exceção de 4\% da malha que foi privatizada e que possui 56 mil quilômetros de rodovia. O DER (Departamento de Estradas e Rodagens) possui missão para administrar o sistema rodoviário estadual, regulamentando as condições de circulação, por meio de decretos, leis e portarias. A Agência Nacional de Transportes Terrestres (ANTT), que foi criada no governo de Fernando Henrique Cardoso, assegura através de portarias e resoluções, os direitos e deveres do cidadão e das empresas de transporte.

Em caso de infração de trânsito, a multa é repassada ao cegonheiro, sendo essa prática comum a todas as empresas de transporte rodoviário de cargas.

\subsubsection{As sobrejornadas de trabalho e a pressão temporal}

Ao serem informados sobre alguma limitação de rodagem durante o dia, os cegonheiros preferem viajar mais tarde, ou seja, ao invés de iniciar a jornada às $08 \mathrm{~h}$, por exemplo, eles podem iniciar às $15 \mathrm{~h}$. Mas, caso tenham outras entregas para fazer, 
pode ocorrer a necessidade de realização de sobrejornadas. Além disso, existem circunstâncias que praticamente impõem o aumento de horas de trabalho. Uma das situações mais relatadas por eles, em relação a esse problema, diz respeito ao Estado de São Paulo, onde as entregas são realizadas fora do horário comercial por determinação da SMT, com o intuito de não impactar no trânsito.

Quando temos que entregar na região de São Paulo, é onde podemos fazer horas extras porque as concessionárias, só recebem os carros após as dez da noite (C6).

Outra situação que pode levar ao aumento da jornada é quando o cegonheiro está próximo ao local de destino e decide finalizar a viagem, seja para realizar a entrega ou mesmo chegar à sua casa.

Seja como for, as sobrejornadas acontecem e são relatadas por todos os entrevistados, mas sem excessos. Em geral, são realizadas 20 horas extras por mês.

Segundo Hoffman (2003), historicamente, os motoristas de caminhão sofriam com o ritmo intenso de trabalho que lhes era imposto, e essa circunstância propiciava maior desgaste, afetando sua saúde, causando inúmeros distúrbios físicos ou mentais e, consequentemente, reduzindo sua qualidade de vida. O alto preço disso foi bem retratado na fala de um cegonheiro:

Antigamente, era desumano! Tudo bem que os valores eram melhores, mas depois a gente gastava com remédios e separação da mulher e o não reconhecimento dos filhos. Hoje, pagamos um bom preço, aliás que nada paga. O da saúde e do convívio com a família. Minha mulher até estranhou no início (risos) (C5).

No caso da empresa pesquisada, ao serem questionados sobre os aspectos positivos e negativos presentes na realização das sobrejornadas, os entrevistados foram unânimes em apontar somente o aspecto positivo uma vez que consideram que são poucas horas, não representando aumento da fadiga, além de trazerem um pequeno ganho financeiro já que recebem em espécie, melhorando o ganho salarial. Portanto, não se constatou qualquer risco à saúde decorrente de ritmos excessivos ou jornadas noturnas elevadas.

Sobre esse aspecto, alguns cegonheiros relataram suas experiências em outras locais onde trabalhavam também com transporte de veículos e eram cobrados por entregas rápidas, comprometendo o descanso e estimulando as sobrejornadas. Segundo o relato de um deles, em uma dessas situações, acabou recorrendo às 
drogas para conseguir atingir o objetivo imposto, sendo que, na empresa estudada, nunca sentiu tal necessidade.

[...] Pra que a gente vai usar drogas aqui na empresa se podemos fazer nosso descanso e não somos acelerados a trabalhar? Em outras empresinhas por aí, até o dono pode oferecer ao cegonheiro um pó para ele render mais. $\mathrm{E}$ rende viu?! Esse caso do dono é extremo, mas já ouvi de colegas. Isso é mais comum do que a gente imagina. Senão, não dá pra estender a jornada (C4).

O mesmo cegonheiro afirmou ainda que, entre os colegas que sofrem pressão temporal, grande parte recorre a essas substâncias, sendo que ele mesmo já presenciou esse problema em um emprego anterior.

No caso da empresa estudada, percebemos que a maioria descartou a possibilidade de cobrança temporal, revelando ter liberdade para lidar com os imprevistos.

\title{
4. A LIMITAÇÃO DA JORNADA DE TRABALHO E SEUS IMPACTOS NA SAÚDE DOS CEGONHEIROS
}

\subsection{A situação anterior à lei do motorista profissional}

Dirigir um grande número de horas por dia tornou-se rotina para os caminhoneiros no nosso país, provavelmente, fruto da organização do trabalho que estabelece prazos curtos para a entrega de mercadorias. Um exemplo disso encontrase na fala de um dos cegonheiros entrevistados:

\begin{abstract}
Quando eu estava em outra empresa, meu chefe me chamou e falou: 'preciso que deixe essa carga em Fortaleza e esteja de volta daqui a quatro dias'. Nessa hora, falei para ele que queria que ele me demitisse. E ele me demitiu. Eu jamais rodaria $1200 \mathrm{~km}$ por dia, pois não teria condição nenhuma. O pior é que sempre tinha quem rodasse. Tinha um menino lá que não dormia e ele era muito jovem. Ele mandava ver nas viagens. Mas eu e alguns colegas sabia como ele conseguia. Droga rolava solta. E não só uma droga, associações de drogas. Teve um dia que alertei ele. Muito novo, não sabia nada da vida e arriscando a vida dele e a dos outros por nada, pois empresa não dá valor. Quando você não presta mais, eles te agradecem e batem nas suas costas: 'valeu enquanto durou'. (C5).
\end{abstract}

Tudo indica que a busca desenfreada por resultados econômicos gerou um trabalho desumano para essa categoria profissional. Antes da Lei do motorista profissional, os caminhoneiros brasileiros podiam ser "enquadrados" no artigo 62, que 
tratava da jornada de trabalho e que dizia o seguinte: "Não são abrangidos pelo regime previsto neste capítulo: (I) os empregados que exercem atividade externa incompatível com a fixação de horário de trabalho, devendo tal condição ser anotada na Carteira de Trabalho e Previdência Social e no registro de empregados". Isso praticamente atuou como uma espécie de liberação da jornada, tendo impactos profundamente negativos nas condições de trabalho dessa categoria.

\subsection{O advento da lei do motorista profissional}

Após o sancionamento da nova lei, cujo teor já foi exposto anteriormente, o artigo 62 não teve mais validade para os motoristas profissionais. Ela também alterou a forma de remuneração do motorista, que passou a receber pelas horas que excederem a jornada prevista. Antes, o profissional não recebia pelas horas extras e sim pela distância percorrida, mas com a interdição de sobrejornadas importantes, sua remuneração final poderá ficar reduzida. No entanto, conforme disseram dois entrevistados, o resultado pode ser mais positivo do que se imagina:

\footnotetext{
A categoria de motoristas de caminhão em geral, de qualquer ramo, sempre recebeu por quilometragem. Aí, quanto mais rodava, mais ganhava. Isso era um vício. Agora, se ganha menos, mas a qualidade de vida é outra. É justamente agora que o mercado e os motoristas estão percebendo esses impactos. Eles conseguem ter a noite de sono, repouso e passar os finais de semana com a mulher, ir ao médico para se cuidar. Em geral, eles estão vendo que o dinheiro não compra tudo isso. (C4)
}

A lei do motorista profissional implicou em uma considerável reestruturação no segmento do transporte de cargas. Ao mesmo tempo em que ela trouxe melhores condições de trabalho, aumentou os custos envolvidos de toda a cadeia logística. Isto gerou uma grande resistência de empregadores e dos seus sindicatos. Ademais, os motoristas tiveram redução do pagamento por produtividade, o que poderia comprometer sua renda. Durante anos, todo esse cenário se sustentou no tripé: baixa remuneração, pagamento por produtividade e descontrole das jornadas de trabalho. Porém, os riscos envolvidos nessa forma de organização da jornada afetaram diretamente a saúde e a segurança desses profissionais, sendo que muitos chegaram ao grau máximo de esgotamento. As consequências disso, como o aumento do uso de drogas pelos motoristas e o número crescente de acidentes, fizeram com que o 
país passasse a se preocupar com o problema e tomasse algumas medidas, dentre elas, a mudança na legislação (MORAES, 2012).

É importante ressaltar ainda que o fundador da empresa pesquisada foi cegonheiro por vários anos e por conhecer a rotina de trabalho e seus riscos, conseguiu desenvolver uma organização diferenciada de trabalho, na qual as pausas são respeitadas, as jornadas são limitadas e a velocidade é bem controlada. Após seu afastamento, o filho que o substituiu, mantém as mesmas diretrizes por julgar que são importantes para o negócio.

A maior evidência de que a empresa desenvolvia boas práticas, foi 0 envolvimento dos próprios donos na elaboração da lei, fazendo com que um deles se mudasse para Brasília, onde permaneceu por dois anos, participando da equipe responsável. Isso foi devido à sua vasta experiência profissional, mas, sobretudo, à aplicação, na sua empresa, de jornadas limitadas e com descanso intrajornadas, desde sua criação.

De acordo com o proprietário, a lei teve "um efeito dominó" que atingiu toda a cadeia logística, desde o consumidor final de veículos e outros produtos, passando pelos proprietários até chegar ao motorista. Todos os motoristas passaram a receber menos por terem mais descanso e o número de viagens ao mês reduziu, impactando no faturamento das empresas.

Ademais, a aprovação da lei fez com que as empresas ficassem sob as lentes das fiscalizações e as consequentes penalidades. Dessa forma, elas estão gradativamente se adaptando ao cumprimento das exigências legais, aprendendo a respeitar as pausas, o que não impede que haja ainda muita transgressão.

\subsection{As mudanças acarretadas pela lei}

As falas dos cegonheiros revelam que a ausência das pausas representava um grave fator de risco no período anterior à limitação da jornada, deixando claro que a mudança gerada pela lei foi positiva:

O pessoal acelerava muito e vários nem dormiam. Sempre foi uma loucura. Isso gerou muita coisa ruim. Essas pausas nos ajudaram demais, você tem horário para rodar e para parar [...]. Em pista simples, só podemos rodar do nascer ao pôr do sol. Na outra empresa que trabalhei, fazia muita hora-extra e gostava. Mas ficava morto de cansado. Cheguei a cochilar no volante. Trabalhando aqui, sempre foi exigido respeitar essas regras. Estranhei, pois, 
imaginava: 'vou parar às 18 horas e ficar à toa até a hora de dormir?' Podia seguir viagem ganhando mais e não ficando à toa. Hoje, que já acostumei, vejo que o descanso é muito importante. Tenho mais disposição para trabalhar, não me canso (C1).

De acordo com os relatos dos entrevistados, as pausas realizadas são reparadoras e eles possuem autonomia e liberdade em relação ao tempo em que devem parar. Todos reconheceram seus benefícios e os impactos positivos no desenvolvimento de seu trabalho e na saúde, uma vez que realizam as pausas durante a jornada de trabalho, além de terem um tempo de repouso diário de onze horas, no mínimo.

A fala a seguir, ilustra bem o que pensa a maioria:

\begin{abstract}
A gente que tá acostumado com a rotina de motorista, se deixar, não para. Porque a gente pensa assim: 'se estou bem, posso desenvolver e resolver 0 problema do cliente'. Entendeu? Aí, pra que esperar? Tempo é dinheiro. Sempre pensei assim. Mas que nada! A gente não tem ideia do cansaço. Sempre achamos que tá tudo bem. Na verdade, quando o corpo sinaliza, às vezes, você está ali, no meio da estrada a ponto de acontecer qualquer coisa. Como já vi muita coisa acontecer. A gente só não imagina que isso pode ser com você. Minha mulher sempre falou e ela tem razão: "qualidade de vida, saúde, é a base de tudo'. Quero viver por muitos anos e essa forma de trabalhar é muito melhor. É como se estivesse dirigindo sempre mais descansado e com mais atenção (C4).
\end{abstract}

Foi observado, portanto, que o descanso, atualmente, é reparador e que os motoristas possuem certa autonomia em relação às pausas, o que representa um excelente mecanismo de regulação da fadiga presente nesse tipo de atividade.

Já é sobejamente conhecido que as pausas, o descanso e o sono, são aspectos de fundamental importância no trabalho de motoristas de caminhão, tendo repercussões diretas na sua saúde, além de ter relação com o uso de substâncias psicoativas. Em 2005, uma pesquisa realizada no Brasil com o objetivo de avaliar a qualidade do sono, o trabalho em turnos, o consumo de álcool e outros psicoestimulantes, além da ocorrência de acidentes entre caminhoneiros, mostrou que 43,2\% dirigiam mais que 16h/dia, sendo que 2,9\% faziam trabalho por turnos e dormiam menos de 5 horas por dia. Além disso, 50,9\% faziam uso de bebida alcoólica, 95,6\% usavam cafeína e 11,1\%, anfetaminas. Nos cinco anos anteriores, 13,1\% dos profissionais pesquisados haviam se envolvido com algum acidente. Os autores concluíram que existia uma alta prevalência de distúrbios do sono, uso de álcool e 
estimulantes, além da grande incidência de acidentes entre os sujeitos estudados (SOUZA; PAIVA; RAIMÃO, 2005).

\subsubsection{Os impactos da lei sobre a saúde}

Os estudos sobre os impactos da nova lei do motorista profissional sobre saúde ainda são incipientes. A única pesquisa à qual tivemos acesso foi realizada pela Confederação Nacional do Transporte (CNT) em agosto de 2016, a qual demonstrou que o principal avanço com a nova lei dos motoristas profissionais e que impacta diretamente na sua saúde, foi o descanso entre as jornadas, respeitando um período mínimo de onze horas, relatado por $16,8 \%$ dos motoristas. Além disso, para 15,4\% dos motoristas, a realização de jornadas de oito horas está sendo efetiva. Os autores concluíram que, a partir da limitação da jornada, os motoristas passaram a gozar do seu tempo de descanso, não havendo mais a necessidade do uso de substâncias psicoativas para permanecerem acordados. Além disso, com a nova lei, ocorreu uma redução considerável dos acidentes nas estradas. Segundo dados fornecidos pela Polícia Rodoviária Federal, somente no Mato Grosso do Sul, os acidentes em rodovias federais reduziram em $47 \%$, após seu advento.

Da mesma forma, em uma palestra ministrada no Setrans ABC (Sindicato das Empresas de Transporte de Carga do ABC) no dia 18 de maio de 2015, Paulo Douglas Almeida de Morais informou que, após a implementação da nova lei, 29.257 acidentes foram evitados, além de terem sido poupadas mais de 15 mil pessoas que não se feriram durante acidentes e quase três mil vidas salvas. Ou seja, essas estatísticas sugerem uma mudança importante no cotidiano dos motoristas, além de aumentar a segurança da população que trafega nas estradas brasileiras.

No caso da empresa pesquisada, como já existia a prática de limitar as jornadas, além de estabelecer pausas para descanso dos motoristas, não foi possível identificar resultados relevantes em relação a mudanças nos índices de acidentes, uma que estes sempre foram muito reduzidos.

O depoimento do gerente operacional demonstra sua satisfação pelos resultados alcançados ao longo dos anos: 
vieram por causa do trabalho. Afastamentos, motoristas que voltavam sem condição de dirigir. Aqui, vejo que não temos problemas desse tipo. Nossos indicadores (de acidentes) quase não existem. São baixíssimos. O problema que temos é de fazer que todos respeitem seu tempo de descanso, pois existe uma minoria que sai da regra. Isso, por mais que sempre tenha sido uma prática, vai muito do costume do profissional que vem de fora. Até ele acostumar, é um processo (G.O.)

Outro resultado relevante, apontado pela pesquisa da CNT, se refere à constatação de que, após a lei, $44,6 \%$ dos motoristas pesquisados estão tendo atitudes preventivas em relação à sua saúde. Este dado se confirmou na nossa pesquisa, sendo que vários motoristas falaram sobre esse cuidado maior com a própria saúde:

Nós temos tempo de ir ao médico. Posso te falar que uso sempre meu plano de saúde. Faço check up porque sei que para o meu trabalho preciso estar bem (C4).

Aproveito as viagens que pego nas cidades mais perto daqui de Betim, $\mathrm{BH}$, porque consigo ir ao médico. Minha mulher sempre pegou no meu pé (C3).

Finalmente, embora tenha havido uma redução no consumo de drogas após a lei, se compararmos com outros estudos já expostos anteriormente, os dados da pesquisa da CNT mostraram que $26,5 \%$ dos motoristas pesquisados ainda fazem uso de algum tipo de substância psicoativa. Podemos supor que esses casos se referem às empresas que não aderiram completamente à nova legislação, aos motoristas que se tornaram dependendes da substância ou que trabalham como autônomos.

\section{CONSIDERAÇÕES FINAIS}

Este estudo tornou ainda mais evidente a importância da regulamentação da jornada do trabalho para a saúde do motorista profissional, trazendo contribuições, tanto em âmbito social quanto organizacional. A pesquisa da CNT reforça essa conclusão, ao revelar que, a partir da regulamentação da sua jornada, os motoristas declararam não precisar mais das drogas psicotrópicas para cumprir os prazos estabelecidos pela empresa. Além disso, o número de acidentes reduziu e os profissionais passaram a dispor de mais tempo para cuidarem da saúde.

É evidente que a lei do motorista profissional, tende a trazer ainda mais benefícios para a categoria e para a sociedade, em geral, na medida em que obtiver 
a adesão das empresas. No entanto, cabe fazer uma ressalva quanto à obrigatoriedade de realização do exame toxicológico, como exigência para que o motorista mantenha sua carteira de habilitação. No nosso entender, o uso de substâncias psicoativas representa apenas a "ponta do iceberg" das dificuldades enfrentadas pelo profissional, uma vez que a decisão sobre seu uso depende, em grande medida, das exigências impostas ao motorista. Essa lei só fará sentido se exigir também o atendimento da regulamentação da jornada, pois, caso contrário, se retirado do motorista o mecanismo de regulação (a substância psicoativa) que o faz suportar as longas jornadas, o perigo tenderá a ser ainda maior do que antes da legislação.

Embora os resultados obtidos tenham demonstrado o lado positivo do trabalho dos cegonheiros, uma vez que a empresa pesquisada representa uma espécie de contraexemplo, em relação ao que ocorre no setor - o que pode ter sido um fator limitador do estudo -, é possível concluir que, se a legislação for cumprida, ocorrerá uma mudança positiva, do ponto de vista da saúde e segurança desses profissionais. Nossos resultados sugerem que, se as empresas adotarem um modelo de organização de trabalho mais flexível, favorável ao descanso e, portanto, à saúde do motorista, esse quadro pode ser revertido.

Vimos que, na empresa estudada, o tempo de trabalho é bem definido, considerando a quilometragem, a condição das estradas e as pausas. As sobrejornadas são esporádicas, reduzindo significativamente o impacto da atividade na fadiga dos profissionais. As pausas são cumpridas e atuam como mecanismo de regulação, prevenção de doenças e até mesmo de acidentes, pois os motoristas trabalham descansados, sem necessidade de uso de drogas psicotrópicas. Ressaltese ainda a autonomia que todos relataram possuir, podendo escolher o melhor momento para usufruírem dessas pausas.

É possível concluir, que essa empresa oferece um bom modelo de gestão e de organização do trabalho, podendo representar uma fonte de inspiração de formas mais justas e humanas de gerir um trabalho reconhecidamente penoso.

\section{REFERÊNCIAS}

AGÊNCIA NACIONAL DE TRANSPORTES TERRESTRES- ANTT. Registro nacional de transportadores de carga. Disponível em: 
<http://appweb2.antt.gov.br/rntrc_numeros/rntrc_TransportadorFrotaTipoVeiculo.asp >. Acesso em: 30 mar. 2015.

ANDRADE, S. S. C. de A. et al. Perfil das vítimas de violências e acidentes atendidas em serviços de urgência e emergência selecionados em capitais brasileiras: vigilância de violências e acidentes, 2009. Epidemiologia e Serviços de Saúde, Brasília, v. 21, n. 1, p. 21-30, mar. 2012. DOI: https://doi.org/10.5123/S1679-49742012000100003

BRASIL. Presidência da República. Lei oㅜ 12.619, de 30 de abril de 2012. Diário Oficial [da] União, Brasília, DF, 2 maio 2012.

CHICO DA BOLEIA. Quais os problemas da nova regulamentação da profissão de motorista? Chico da Boleia, 20 maio 2015. Disponível em:

$<$ http://www.chicodaboleia.com.br/quais-os-problemas-da-nova-regulamentacao-daprofissao-de-motorista/>. Acesso em: 14 out. 2015.

DEPARTAMENTO DE ESTRADAS DE RODAGEM. Secretaria de logística e transportes. Disponível em: < http://www.der.mg.gov.br/institucional/legislacao/leis-decretos> Acesso em: 19 jun.-2016.

DEPARTAMENTO NACIONAL DE INFRAESTRUTURA DE TRANSPORTES. Plano Nacional de Contagem de tráfego. Disponível em: < http://www1.dnit.gov.br/oque.htm>. Acesso em: 19 jun.2016

FERRAZ, E.A. Caminhoneiros: Parcerias do Asfalto - conhecimento, atitudes e práticas sobre o HIV/Aids em Uberlândia - 2005, Rio de Janeiro: BEMFAM, 288p.

FERREIRA, S. de S.; ALVAREZ, D. Organização do trabalho e comprometimento da saúde: um estudo em caminhoneiros. Sistemas \& Gestão, Niterói, v. 8, n. 1, p. 58-66, 2013. DOI: https://doi.org/10.7177/sg.2013.v8.n1.a5

HOFFMAN, A. L. Qualidade de vida dos motoristas de caminhão usuários do Programa Rodopac: um estudo de caso. 2003. 82 f. Dissertação (Mestrado em Engenharia de Produção) - Programa de Pós-Graduação em Engenharia de Produção, Universidade Federal de Santa Catarina. Florianópolis, 2003.

LACERDA, R. et al. Truck drivers in Brazil: prevalence of HIV and other sexually transmitted diseases, risk behavior and potential for spread of infection. AIDS, 11(Suppl 1):S15-19, 1997.

LYZNICKI, J. M. et al. Sleepiness, driving, and motor vehicle crashes. Journal of the American Medical Association, v. 279, n. 23, p. 1908-1193, 1998.

DOI: https://doi.org/10.1001/jama.279.23.1908

MASSON, V. A.; MONTEIRO, M. I. Estilo de vida, aspectos de saúde e trabalho de motoristas de caminhão. Revista Brasileira de Enfermagem, Brasília, v. 63, n. 4, p. 533540, jul./ago. 2010.

MCCARTT, A. T. et al. Factors associated with falling asleep at the wheel among longdistance truck drivers. Accident Analysis and Prevention, v. 32, n. 4, p. 493-504, 2000. DOI: https://doi.org/10.1016/S0001-4575(99)00067-6

MORAES, P. D. A. de. A dignidade do trabalhador e o meio ambiente do trabalho no setor de transporte. Revista do TST, Brasília, v. 80, n. 1, p. 78-87, jan./mar. 2014. 
MORAES, P. D. A. Regulamentação da profissão do motorista. 2012. Disponível em: < https://regulamentacao.wordpress.com/2012/08/30/procurador-do-trabalho-do-ms-dr-paulodouglas-fala-sobre-a-regulamentacao/>. Acesso em: 09 jun.2016

MORENO, C. R. C.; ROTEMBERG, L. Fatores determinantes da atividade dos cegonheiros de caminhão e repercussões à saúde: um olhar a partir da análise coletiva do trabalho.

Revista Brasileira de Saúde Ocupacional, São Paulo, v. 34, n. 120, p. 128-138, 2009.

DOI: https://doi.org/10.1590/S0303-76572009000200004

NASCIMENTO, E. C.; NASCIMENTO, E.; SILVA, J. D. Uso de álcool e anfetaminas entre caminhoneiros de estrada. Saúde Pública, p. 290-293, 2007.

PESQUISA CNT DE PERFIL DOS CAMINHONEIROS 2016 - Brasília:CNT 2016. Disponível em:

http://cms.cnt.org.br/Imagens\%20CNT/PDFs\%20CNT/Pesquisa\%20de\%20Perfil\%20dos\%2 0Caminhoneiros/Pesquisa_CNT_de_Perfil_dos_Caminhoneiros_2016_Completo.pdf..

Acesso em: 30 ago. 2016.

SANTOS, L. Moro no mundo e passeio em casa: vida e trabalho dos caminhoneiros. In: ANTUNES, R.; SILVA, M. A. M. O Avesso do trabalho. São Paulo: Expressão Popular, 2004. p. 285-353.

SECRETARIA MUNICIPAL DE TRANSPORTES. Transparência Pública Licitações e Contratos. Disponível em: <http://www.cetsp.com.br/consultas/caminhoes.aspx>. Acesso em: 19 jun. 2016

SILVA, O.A., GREVE, J.M.D., YONAMINE, M., LEYTON, V. Drug use by truck drivers in Brazil. Drugs Educ Prev Policy. v.10, n. 2, p. 135-9, 2003.

DOI: https://doi.org/10.1080/0968763021000057727

SINDICATO DAS EMPRESAS DE TRANSPORTE DE CARGA DO ABC. Quais os problemas da nova regulamentação da profissão de motorista? Disponível em: < http://www.chicodaboleia.com.br/quais-os-problemas-da-nova-regulamentacao-da-profissaode-motorista>. Acesso em: 19 jun. 2016

SOUZA, J. R.; PAIVA, T.; REIMÃO, R. Sleep habits, sleepiness and accidents among truck drivers. Arquivos de Neuro-Psiquiatria, São Paulo, v. 63, n. 4, p. 925-930, dez. 2005. DOI:https://doi.org/10.1590/S0004-282X2005000600004

STRATFORD, D., ELLERBROCK, T.V., AKINS, J.K., et al. Highway cowboys, old hands, and Christian truckers: risk behavior for human immunodeficiency virus infection among long-haul truckers in Florida. Soc Sci Med. 2000;50:737-49.

DOI: https://doi.org/10.1016/S0277-9536(99)00335-4

THIRY-CHERQUES, H. R. Saturação em pesquisa qualitativa: estimativa empírica de dimensionamento. Revista Brasileira de Pesquisas de Marketing, Opinião e Mídia, São Paulo, n. 3, p. 20-27, set. 2009.

TRT/RS - Guia trabalhista: a tecnologia afasta a incidência do art. 62 da CLT. 25/06/2012. Disponível em: http://www.guiatrabalhista.com.br/tematicas/horasextrastrabalhoexterno.htm. Acesso em: 22 jul. 2016. 
UBAIDULLAH M. Social vaccine for HIV prevention: a study on truck drivers in South India. Sc Work Health Care, v. 39, n. 3/4, p. 399-414, 2004.

DOI: https://doi.org/10.1300/J010v39n03 11

ULHÔA, M. A. et al. Distúrbios psíquicos menores e condições de trabalho em motoristas de caminhão. Revista de Saúde Pública, São Paulo, v. 44, n. 6, p. 1130-1136, dez. 2010. DOI: https://doi.org/10.1590/S0034-89102010000600019

WALTRICH, D. Q. A necessidade de implementação de políticas públicas tributárias que garantam efetividade a Lei n. 12.619, de 30 de abril de 2012, que regulamenta a profissão de motorista. In: SEMINÁRIO INTERNACIONAL DE DEMANDAS SOCIAIS E POLÍTICAS PÚBLICAS NA SOCIEDADE CONTEMPORÂNEA, 11., 2014, Santa Cruz do Sul. Anais... Santa Cruz do Sul: UNISC, 2014.

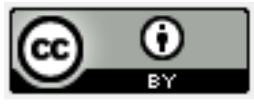

Artigo recebido em 14/11/2016 e aceito para publicação em 02/05/2018 DOI: http://dx.doi.org/10.14488/1676-1901.v18i2.2622 